\title{
The Effect of Mind Subtraction Meditation on Smartphone Addiction in School Children
}

\author{
Yang Gyeong Yoo ${ }^{1}$, Min Jeong Lee ${ }^{2}$, Boas $\mathrm{Yu}^{3} \&$ Mi Ra Yun ${ }^{4}$ \\ ${ }^{1}$ Department of Nursing, Kunsan National University, South Korea \\ ${ }^{2}$ Kimhae Sammun School, South Korea \\ ${ }^{3}$ School of Nursing and Allied Health, Fairleigh Dickinson University, USA \\ ${ }^{4}$ College of Nursing, Chung-Ang University, South Korea \\ Correspondence: Boas Yu, EdD, RN, FNP-BC, PMHNP-BC, CNE, GCNS, Associate Professor, Henry P. Becton \\ School of Nursing and Allied Health, Fairleigh Dickinson University, 1000 River Rd. Teaneck, NJ 07666, USA. \\ Tel: 201-692-2881. E-mail: byu@fdu.edu
}

Received: July 5, 2019 Accepted: July 24, 2019 Online Published: July 29, 2019

doi:10.5539/gjhs.v11n10p16 URL: https://doi.org/10.5539/gjhs.v11n10p16

\begin{abstract}
Background: Aim of current study was to examine the effects of school-based mind subtraction meditation program on smartphone addiction tendency and mental health of third grade students in a South Korean elementary school.
\end{abstract}

Materials and Methods: A quasi-experimental design with nonequivalent comparison groups was used. An experimental group $(\mathrm{n}=24)$, who participated in the school-based meditation program, and a control group ( $\mathrm{n}=$ 22), who did not participate in the program, were measured pre-test, post-test, and also three months after the completion of this study on smartphone addiction tendency and mental health.

Results: The study result showed a significant decrease in smartphone addiction tendency and also significant improvements in mental health variables of depression, anxiety, aggression, and impulsivity for the experimental group. These improvements were shown to continue even after the study completion when measured post-intervention at three months.

Conclusion: This study demonstrated that the mind subtraction meditation program had positive effects on smartphone addiction tendency and mental health variables. It can be suggested from this study to recommend mind subtraction meditation as one of feasible strategies to prevent smartphone addiction and to improve mental health status in elementary school children. Further, this study meaningfully supports positive beneficial evidence of meditation program utilization in schools.

Keywords: elementary school students, mental health, mind subtraction meditation, smartphone addiction tendency

\section{Background}

\subsection{Introduction and Main Research Area}

When examining current available statistics on utilization of smartphones among South Korean youth, the data indicates a steep increase. According to Ju and Cho (2015), the utilization among the youth in 2011 was shown to be at $21.4 \%$; which increased to $64.5 \%$ (2012) and 81.5\% (2013). Smartphones have become very popular due to its portability and convenience of usage but dysfunctional aspect of this popularity includes smartphone addiction. Such addiction may stem from overly frequent, severe smartphone habitual usage which cannot be self-controlled and cause disturbances in living everyday life leading to depression, nervousness, and anxiety (South Korean Ministry of Education, Science and Technology, 2012; South Korean National Information Society Agency, 2013; Kang, 2014; Jun \& Kim, 2015). Because a smartphone is convenient to use and provides instant gratification with the ease of portability, this seemed to have much stronger addiction potential than internet addiction (Kim \& Hwang, 2015).

The South Korean statistical data shows the seriousness of this problem. According to a 2014 smartphone addiction study $(n=15000)$ conducted by South Korean National Information Society Agency and Ministry of 
Science, ICT, and Future Planning, 29.2\% were identified as youth at risk (aged 10 to 19 years old). Of the smartphone users aged 10 to 59 years old in this study, the younger the age, the higher the addiction risk with $19.6 \%$ (20 to 29 years old), $11.3 \%$ (30 to 39 years old), $7.9 \%$ (40 to 49 years old), and $4.8 \%$ (50 to 59 years old) (South Korean Ministry of Science, ICT, and Future Planning, 2015). The analyzed data in this study showed South Korean teenagers had at least twice the risk (and in some cases as high as 5 times the risk) than adults.

This may be due to smartphone's attractive appeal to youth with portable games, music, social, and other apps which can be purchased and downloaded instantaneously. Shin (2014) reports this addiction risk can be related to South Korea's particularly stressful educational environment with a steep increase in use of private academic tutoring service occurring after school for elementary school students $(84.6 \%)$, middle school students (71\%), and high school students (58.7\%). Due to this overemphasis on educational competition in youth, children aged 9 to 11 showed high anxiety levels similar to that of adults with anxiety complaints (Yoon \& Eun, 2014). According to Shin (2014), currently there are no specific programs or strategies in schools to manage or relieve the high levels of educational stress, which may lead to students' increased smartphone use for stress relief. Such smartphone addiction can lead to many physical problems; for example, it could lead to sleep disorders, turtle neck syndrome, carpal tunnel syndrome, and overall physical weakness due to physical inactivity (Lee, Kang \& Shin, 2015). But the most serious problem could occur in mental health. According to other smartphone research studies on youth, smartphone addiction can lead to various mental issues such as anxiety, depression, obsessive-compulsive neurosis, aggression, impulsivity, and relationship avoidance (Keum, 2013; Kim, 2013; Park, 2013; Pak, 2013; Yoon, 2013; Jung, 2014; Hong, 2013; Kang, 2014).

A 2013 report by South Korean National Information Society Agency on internet and smartphone use points out that smartphone addiction is as serious for elementary school students as it is for middle and high school students; due to brain immaturity, it is riskier in younger age groups and negative effects of addiction can persist into adulthood (Kim, Yu, \& Nam, 2015).

Elementary school years are very important time to learn and develop empathy, morality, and other social skills (Kang \& Park, 2012). Smartphone addiction occurring in such a young age could hamper proper development and lead to social isolation and difficulties in forming relationships (Kim, Han, \& Park, 2014). Therefore, it is significant, if not imperative, to design strategies with the aim to decrease smartphone addiction in youth, especially in the younger age group.

\subsection{Review of Literature}

In an attempt to understand the importance of the current research, the following areas will be discussed in depth as they related to the area concerned: smartphone addiction and mind subtraction meditation.

\subsubsection{Smartphone Addiction}

When examining smartphone addiction research studies, most of the studies consisted of: use of smartphone (Kim, 2013); smartphone addiction factors (Jun, 2013; Choi, 2013; Hong, 2013; Chu \& Cho, 2015; Kang, 2014); consequences associated with smartphone addiction (Kim, 2013; Moon, 2013; Park, 2013 Park, 2011; Jun \& Kim, 2015). To date, many smartphone addiction studies were conducted in South Korea and also other countries including Taiwan (Lin et al., 2014; Lin et al., 2015); India (Davey \& Davey, 2014); Switzerland (Haug, Castro, Kwon, Filler, Kowatsch, \& Schaub, 2015); and the United States (Roberts, Yaya, \& Manolis, 2014; Smetaniuk, 2014). However, studies to examine smartphone addiction preventive programs and effects of interventional efforts seem lacking (Kim, Yu, \& Jung, 2014; Rhu \& Cho, 2015). Many studies did focus on smartphone addiction and its various consequences; nonetheless, practical strategies for the addiction remained insufficient. Smartphone addiction studies should now focus on preventive efforts as well as interventional strategies (Kim, Yu \& Jung, 2014; Rhu \& Cho, 2015).

When reviewing other studies on smartphone addiction, the most problematic mental health factors were identified as anxiety, depression, impulsivity and aggression (Kwon, 2013; Hwang, Yu, \& Cho, 2012; Lee, 2014; Sun \& Bak, 2015; Park \& Park, 2014; Rhu \& Cho, 2015). According to Kwon (2013), higher level of smartphone addiction was associated with higher anxiety and depression levels; and Hwang, Yu and Cho (2012) found negative emotions related to anxious state, anxiety trait, and depression were shown to be possible factors to increase smartphone addiction tendency. Lee (2014) also reported that with higher levels of smartphone addiction, impulsivity level was higher. Inversely, Rhu and Cho (2015) found that with higher impulsivity, smartphone addiction was higher.

For aggression in children, Sun and Bak (2015) found there was an increase in aggression with higher level of smartphone addiction; Park and Park (2014) reported higher aggression was associated with higher level of smartphone addiction. Four mental health variables consisting of anxiety, depression, impulsivity, and aggression 
seemed to be associated with smartphone addiction according to the previous studies (Kwon, 2013; Hwang, Yu, \& Cho, 2012; Lee, 2014; Sun \& Bak, 2015; Park \& Park, 2014; Rhu \& Cho, 2015). Henceforth, it can be predicted that if these variables can be improved, smartphone addiction could be alleviated or eased.

\subsubsection{Mind Subtraction Meditation}

The meditation is based on holistic and cosmological concepts focusing on true nature of human beings and pure absolute acceptance of the original mind of Universe (Universe mind). All human beings are born with this original mind, but while living out their lives, memories of lived experiences (including emotions, senses, feelings, and perceptions) accumulate in their minds (Woo, 1996). In this study, a school-based meditation program was chosen as an intervention since the program was shown to have positive effects on these four variables in particular (anxiety, depression, impulsivity, and aggression). Yoo et al. (2016) reported significant decreases in social anxiety, aggression, and salivary cortisol level (physiological indicator of stress) for elementary school $5^{\text {th }}$ graders when participating in a school-based meditation program utilizing mind subtraction meditation. Other studies using similar mind subtraction meditation programs in schools also reported significant improvements in the following: depression and anxiety for youth (Kim, 2012); anxiety related to school, home, examination, societal, and situational stress in $5^{\text {th }}$ graders with documented high anxiety symptoms and complaints (Ahn, 2006); trait and state anxiety in middle school students (Choi, Lee, \& Cheon, 2006); aggression in elementary and middle school students (Kim, Yoo, Lee, \& Son, 2013); and self-control in elementary, middle, and high school students (Yoo, Yoon, Choi, \& Kim, 2014).

Wisner, Jones and Gwin (2010) states that school-based meditation programs can be one of innovative strategies for students facing many academic, psychosocial, and behavioral demands of today. Such programs occurring within school grounds can also be positive influence for improving school environment and atmosphere (Wisner, 2008). Many studies demonstrated positive mental health benefits of meditation programs housed within schools, ranging from academic enhancement, decreased anxiety, to improved independence, self-reliance and self-esteem (Barnes, Bauza, \& Treiber, 2003; Beauchemin, Hutchins, \& Patterson, 2008; Benson, Kornhaber, Kornhaber, LeChanu, Zuttermeister, Myers, \& Friedman, 1994; Rosaen \& Benn, 2006; So \& Orme-Johnson, 2001; Wisner, 2008).

The mind subtraction meditation is utilized widely in South Korea as a part of humanistic education program due to its sound scientific and systematic method (Jeong, Kim, Kim, \& Kim, 2015). Further, this meditation was incorporated into popular summer youth camp programs for the last 17 years, and many studies examined its positive effects in camps and schools (Kim, 2012; Kim, Yoo, Lee, \& Son, 2013; Lee, 2010; Kwak, 2005; Kwak, 2009; Yoo, Lee, \& Jung, 2013; Lee, 2009; Yoo \& Lee, 2013).

Due to the popularity of the mind subtraction meditation for humanistic education in schools, this present study focused on the meditation to examine its effect on smartphone addiction reduction and mental health. The meditation was founded by Woo (1996) and it consists of a process of concentration and self-reflection (Jeong et al., 2015).

This accumulated mind is a false mind which filters the world one sees and one becomes imprisoned in the false mind of misperceptions and misinterpretations (Woo, 1996). Because one would see the world through this self-created filter (false mind), one would be confined to one's own mind world which is different from the true world outside, leading to difficulties such as stress, anger, anxiety, and depression. The mind subtraction meditation method focuses on subtracting the false mind (full of misinterpretations, misperceptions, and misunderstandings) so that the original mind would emerge (Jeong et al., 2015).

Furthermore, the meditation is able to define what is human mind and provide a specific and systematic method which can be practiced by anyone, even elementary school students. The merits of transformative changes and positive benefits were consistently gained by those who practice the meditation even in relatively short time duration of practice (Yoo, Lee, \& Jung, 2013; Lee, 2009; Yoo et al., 2016). The method of subtracting the false mind is very simple and regardless of age or education, anyone can practice it (Woo, 1996). As one follows the method and continue practicing, the false mind gradually moves toward the original mind. The principles and concepts of the meditation, which may have been difficult to understand in the beginning, would be easier to comprehend as one cleans the false mind. This increase in comprehension, or enlightenment, would be one of the special characteristics which differs from any other educational programs, since this enlightenment occurs through cleansing or emptying of the false mind, not by adding new knowledge or information as it normally occurs in the conventional sense of modern education (Woo, 1996).

At the present time, the mind subtraction meditation is offered in various settings, such as government agencies 
and offices, business organizations and companies, colleges and universities, and youth camps in South Korea and other countries (www.meditationlife.org). Due to increased demand for a humanistic education focus in schools, the meditation program is offered at schools in different formats: after-school programs, creative experience and activity programs, curricular courses (as required courses or elective courses) (http://www.ihumancom.net/news/articleView.html?idxno=295). In this study, third grade elementary school students were offered the mind subtraction meditation program to examine its effects on smartphone addiction tendency, depression, anxiety, aggression, and impulsivity. Even though many research studies are available supporting benefits of the meditation, there were no studies related to this age group to date.

\section{Theoretical Framework: Pender's Health Promotional Model (PHPM)}

The Health Promotion Model by Pender (2011) is one of the most widely used models to change unhealthy behaviors and to promote health. The model is extensively utilized in nursing research, education, and practice; it focuses on assisting people to achieve higher levels of well-being (McCutcheon, Schaar \& Parker, 2016). Three main areas are emphasized in this theory: individual characteristics and experiences, behavior-specific cognitions and affect, and behavioral outcomes. Four assumptions of the model are deemed important in guiding this study: individuals seek to actively regulate their own behavior; individuals, in all their biopsychosocial complexity, interact with the environment; health professionals such as nurses, constitute a part of the interpersonal environment which exerts influence on people through their life span; and self-initiated reconfiguration of the person-environment interactive patterns is essential to changing behavior.

\section{Purpose}

The purpose of this study was to examine the effect of a school-based mind subtraction meditation program on smartphone addiction tendency and addiction-associated mental health variables which are depression, anxiety, impulsivity, and aggression. More specifically, this study examined if there were any reductions in smartphone addiction tendency and if there were any improvement in depression, anxiety, impulsivity, and aggression. It is hoped that through this study, we could expand on the utilization of this meditation in educational settings for humanistic education purposes and provide some basis for feasible strategies to prevent smartphone addiction.

\section{Method}

\subsection{Research Questions}

The study asked the following research questions:

1). Is the meditation effective in reducing smartphone addiction tendency for the experimental group at post-intervention and at three months after the intervention?

2). Is the meditation effective in improving mental health for the experimental group at post-intervention and at three months after the intervention?

a). Is the meditation effective in reducing depression for the experimental group at post-intervention and at three months after the intervention?

b). Is the meditation effective in reducing anxiety for the experimental group at post-intervention and at three months after the intervention?

c). Is the meditation effective in reducing impulsivity for the experimental group at post-intervention and at three months after the intervention?

d). Is the meditation effective in reducing aggression for the experimental group at post-intervention and at three months after the intervention?

\subsection{Design}

This non-randomized study examined the effect of mind subtraction meditation using a quasi-experimental design with pretest and posttest using nonequivalent comparison groups. This study used convenience sampling; for example, if the students were already assigned to a classroom chosen for the intervention, they received the meditation program. Three months after completion of the study, measurements were repeated. This was based on recommendations to examine the sustained effect of the meditation in order to assist planning meditation program in schools (Choi, Lee \& Chun, 2006).

\subsection{Participants}

The participants were all $3^{\text {rd }}$ graders of an elementary school in South Korea. The experimental group consisted of 22 students and the control group consisted of 24 students for a total of 46 students. The control group participants 
were from the same school although the classroom was physically located farther from the experimental group's classroom.

The elementary school was located within a large urban setting with many multiple dwelling apartments and other adjacent schools. This school was designated by a government educational agency as an exemplar school for extracurricular sports activities with an emphasis on physical health and school violence prevention efforts. The educational levels and economic status of parents were high with much attention paid to children's academic performance. Many students received private tutoring or attended after-school tutoring schools for mathematics, writing, English, and other subjects. Due to the high academic pressure and competition even at the elementary school level, many students of this school were stressed but were not supported through school-based programs.

Using a statistical power analysis with the G-power 3 program, the effect size of 0.5 with a power of 0.9 (two-way alpha; $p=.05$ ) was calculated (Faul, Erdfelder, Lang \& Buchner, 2007), which suggested a minimum of 21 participants in each group. The study's purpose, procedures, confidentiality, voluntary participation, potential risks and benefits, and rights to withdraw from the study without penalty were explained to the participants. All students and their parents consented to the study before participating. The attrition rate was $0 \%$ with no students dropping out of the study. All participating students were without any history of physical or mental health issues and did not have any meditation experience prior to the study.

\subsection{Measures}

To examine the smartphone addiction tendency, Smartphone Addiction Inventory developed by Kang and Park (2012) was relied upon. The inventory is a 23- item Likert scale with a higher score indicating higher smartphone addiction. The research by Kang and Park (2012) indicated Cronbach's $\alpha$ as 0.86 and for this study Cronbach's $\alpha$ was 0.93 (pretest).

To evaluate mental health, we used the NEO personality assessment system (NEO-PAS) developed by Kim and Ahn (2006) to measure four variables associated with smartphone addiction, depression ( 8 items), anxiety (8 items), impulsivity ( 8 items), and aggression ( 8 items). Kim and Ahn (2006) stated Cronbach's $\alpha$ as 0.86 for depression, 0.88 for anxiety, 0.78 for impulsivity, 0.87 for aggression (Keum, 2013). For this study, pretest Cronbach's $\alpha$ was 0.80 for depression, 0.91 for anxiety, 0.87 for impulsivity, 0.88 for aggression.

\subsection{Procedure}

A college in South Korea near the elementary school gave an Internal Review Board (IRB) approval in March, 2015. To develop a meditation program, we explored other research studies using the mind subtraction meditation method with third graders in youth camps and schools (Lee, 2009; Yoo \& Lee, 2013). Six elementary school teachers experienced with school-based meditation programs and three educational experts from colleges were consulted to design a meditation program. Decisions were made to offer 30-minute meditation sessions three times a week for 8 weeks for a total of 24 sessions.

The meditation method consists of 7 progressive levels, which requires mastery of each level to move on to the next level (www.meditationlife.org). Only the first level method was used for the interest of this study (see Table 1 for the mind subtraction meditation levels). Main contents of the program were subtractions of daily experiences (and related thoughts, emotions, mindsets, etc.) and subtractions based on selected topics (stressful memories). To assist in the meditation practice, students were given explanations about the meditation using familiar storybooks, videos, and powerpoint presentations.

The meditation sessions were administered by a credentialed school teacher with a mind subtraction meditation instructor certificate. The instructor attended an intensive 8-hour workshop on school-based meditation programs prior to this study; and also had extensive experience in instructing meditation to elementary school students, parents, and fellow teachers in various settings over many years.

Before this study was conducted, a small pilot study using 10 elementary school third grade students was completed to examine age-appropriateness of questionnaires used and modified some of questions so it would be easier to comprehend for the third graders. The investigators explained the purpose of this study and data collection method to the students' homeroom teachers, in addition to parents and students involved in this study. All necessary consent forms and related documentations were completed prior to this study. The homeroom teachers assisted the paper and pencil questionnaire entries by the students in the event they did not understand the questions.

The experimental group received the meditation session for eight weeks for a total of twenty-four sessions. The control group did not receive any intervention. Both groups were measured pretest, posttest, and after three months 
of study completion. Posttest was completed after eight weeks of the meditation program and another post-study completion measurement occurred after three months. All data collections for both experimental and control groups were taken on same days for pretest, posttest, and after three month measurements.

Table 1. The mind subtraction meditation: 7 levels

\begin{tabular}{lll}
\hline Levels & Enlightenments achieved per level & Method \\
\hline 1 & Knowing that I am the universe & $\begin{array}{l}\text { Subtracting memorized thoughts } \\
\text { (Example: remembering stressful events and throwing them away) }\end{array}$ \\
\hline 3 & Knowing there is no human mind & $\begin{array}{l}\text { Subtracting self and others' images } \\
\text { (Example: bringing up negative self-images and throwing them away) }\end{array}$ \\
\hline 4 & Knowing that there is universe in & $\begin{array}{l}\text { Subtracting my body } \\
\text { (Example: bringing up memories of illness and throwing them away) }\end{array}$ \\
\hline 5 & Knowing the true mind and true & $\begin{array}{l}\text { Subtracting my body and universe } \\
\text { (Example: throwing away negative self-perceptions about body) }\end{array}$ \\
\hline 6 & Borld & (Example: throwing away body-images) \\
\hline 7 & Becoming the true self & $\begin{array}{l}\text { Subtracting self and become universe } \\
\text { (Example: self-reflect on lived experience and throwing them away) }\end{array}$ \\
\hline
\end{tabular}

\section{Results}

The data analysis was completed using IBM SPSS Statistics 20.0. To analyze the effect of the meditation program, t-tests were used to compare the pretest and posttest scores in anxiety, depression, aggression, and impulsivity. Using ANCOVA, the differences in intervention results were analyzed with controlling for pretest scores. Paired t-tests were used to compare smartphone addiction tendency and mental health variables at pretest, posttest, and after 3 months. Repeated measure analysis of variance (ANOVA) was utilized for examining score patterns of smartphone addiction tendency and those four mental health variables over time.

The experimental and control group participants were all third graders in the same elementary school. Table 2 shows a comparison of the groups' characteristics in terms of the following: $\operatorname{gender}\left(\chi^{2}=0.000, p=1.000\right)$ type of smartphone $\left(\chi^{2}=3.008, p=0.222\right)$, received education about phone use $\left(\chi^{2}=1.917, p=0.166\right)$, satisfaction with school $\left(\chi^{2}=9.381, p=0.052\right)$, school stress $\left(\chi^{2}=5.111, p=0.276\right)$, experience with school violence $\left(\chi^{2}=2.185, p=0.139\right)$, time duration of smartphone use $\left.\mathrm{t}=-0.019, p=0.985\right)$, time duration of computer use $(t=1.248, p=0.222)$, total week day use of games $\mathrm{t}=-0.215, p=0.831)$, total weekend use of games $(t=0.660, p=0.513)$, total time duration with TV watching $(t=0.461, p=0.647)$, and frequency of education about phone use $(t=-1.366, p=0.185)$. Although not proving homogeneity, it shows that there is no significant difference between the groups.

The experimental group's average smartphone addiction tendency at pretest was 1.74 and for the control group, it was 1.47 (see Table 3). For the mental health measurement, there was a difference between the groups; the experimental group's pretest average mental health was 2.00 and for the control group, it was 1.40.

Examining the difference in mental health subset pretest scores, the experimental group's depression score average was higher at 1.84 and for the control group it was 1.40. The average anxiety score for the experimental group was also higher at 2.19 and for the control group, it was 1.42 . The experimental group's pretest average impulsivity score was 2.03 and for the control group it was 1.41; for aggression, the experimental group was 1.92 and for the control group it was 1.38 .

Table 3 lists average posttest results on smartphone addiction tendency and mental health variables using ANCOVA. Statistically significant posttest results were shown on both smartphone addiction tendency and mental health variables. For the experimental group, smartphone addiction tendency was $1.74( \pm .71)$ pretest and $1.10( \pm .15)$ 
posttest and for the control group, it was $1.47( \pm .57)$ pretest and $1.69( \pm .52)$ posttest, which speaks to the likelihood of improvement in smartphone addiction tendency with the meditation program. As for mental health, for the experimental group's pretest was $2.00( \pm .58)$, and posttest was $1.16( \pm .24)$ and for the control group, it was $1.40( \pm .46)$ pretest, $1.85( \pm .57)$ posttest.

Table 4 shows average changes occurring over time in variables of smartphone addiction tendency and mental health for both group. Statistically significant changes were seen with smartphone addiction tendency, mental health and its subsets of depression, anxiety, impulsivity, and aggression over time. However, post-intervention at 3 months shows non-significant results for smartphone addiction tendency and depression.

Table 2. Homogeneity test between experimental and control groups $(\mathrm{N}=46)$

\begin{tabular}{|c|c|c|c|c|}
\hline \multirow{2}{*}{ Characteristics } & & Exp. $(n=22)$ & Cont. $(n=24)$ & \multirow{2}{*}{$\mathrm{x}^{2}$ or $\mathrm{t}(P)$} \\
\hline & & $\mathrm{N}(\%)$ or $\mathrm{M}( \pm \mathrm{SD})$ & $\mathrm{N}(\%)$ or $\mathrm{M}( \pm \mathrm{SD})$ & \\
\hline \multirow{2}{*}{ Gender } & Male & $11(50.0)$ & $12(50.0)$ & \multirow{2}{*}{$.000(1.000)$} \\
\hline & Female & $11(50.0)$ & $12(50.0)$ & \\
\hline \multirow{3}{*}{ Types of phones } & Smartphones & $9(40.9)$ & $11(45.8)$ & \multirow{3}{*}{$3.008(0.222)$} \\
\hline & Non-smartphones & $6(27.3)$ & $2(8.3)$ & \\
\hline & Don't own mobile phones & $7(31.8)$ & $11(45.8)$ & \\
\hline \multirow{2}{*}{ Received education about phone use } & No & $22(100)$ & $22(91.7)$ & \multirow{2}{*}{$1.917(0.166)$} \\
\hline & Yes & $0(0)$ & $2(8.3)$ & \\
\hline \multirow{5}{*}{ School life satisfaction } & Very unsatisfied & $2(9.1)$ & $0(0)$ & \multirow{5}{*}{$9.381(0.052)$} \\
\hline & unsatisfied & $5(22.7)$ & $0(0)$ & \\
\hline & Neutral & $5(22.7)$ & $6(25.0)$ & \\
\hline & Satisfied & $5(22.7)$ & $10(41.7)$ & \\
\hline & Very satisfied & $5(22.7)$ & $8(33.3)$ & \\
\hline \multirow{5}{*}{ School life stress } & Very much & $2(9.1)$ & $0(0)$ & \multirow{5}{*}{$5.111(0.276)$} \\
\hline & A lot & $5(22.7)$ & $5(20.8)$ & \\
\hline & Neutral & $5(22.7)$ & $4(16.7)$ & \\
\hline & A little & $7(31.8)$ & $6(25.0)$ & \\
\hline & None & $3(13.6)$ & $9(37.5)$ & \\
\hline \multirow{2}{*}{ School violence experience } & No & $13(59.1)$ & 19(79.2) & \multirow{2}{*}{$2.185(0.139)$} \\
\hline & Yes & $9(40.9)$ & $5(20.8)$ & \\
\hline Length of smartphone use & & $36.14( \pm 34.74)$ & $36.33( \pm 35.56)$ & $-0.019(0.985)$ \\
\hline Length of computer use & & $63.50( \pm 73.18)$ & $42.08( \pm 35.06)$ & $1.248(0.222)$ \\
\hline $\begin{array}{l}\text { Total time of game activities } \\
\text { (weekdays) }\end{array}$ & & $46.82( \pm 69.12)$ & $50.67( \pm 51.81)$ & $-0.215(0.831)$ \\
\hline $\begin{array}{l}\text { Total time of game activities } \\
\text { (weekends) }\end{array}$ & & $102.27( \pm 110.62)$ & $84.08( \pm 74.32)$ & $0.660(0.513)$ \\
\hline Total time of watching TV daily & & $138.82( \pm 74.72)$ & $127.50( \pm 90.30)$ & $0.461(0.647)$ \\
\hline Frequency of phone use education & & $.00( \pm .00)$ & $0.13( \pm 0.45)$ & $-1.366(0.185)$ \\
\hline
\end{tabular}

Exp.=Experimental group; Cont. $=$ Control group. 
Table 3. The effect of school-based mind subtraction meditation on variables: pretest and posttest only $(\mathrm{N}=46)$

\begin{tabular}{|c|c|c|c|c|c|c|c|c|}
\hline \multirow{2}{*}{$\begin{array}{l}\text { Variables } \\
\text { Variables }\end{array}$} & \multicolumn{3}{|c|}{ Exp. $(n=22)$} & \multicolumn{3}{|c|}{ Cont. $(n=24)$} & \multirow[b]{2}{*}{$\begin{array}{l}\text { Effect } \\
\text { size }\end{array}$} & \multirow[b]{2}{*}{$\begin{array}{c}\text { ANCOVA } \\
(p)\end{array}$} \\
\hline & $\begin{array}{l}\text { Pretest } \\
\mathrm{M} \pm \mathrm{SD}\end{array}$ & $\begin{array}{l}\text { Posttest } \\
\mathrm{M} \pm \mathrm{SD}\end{array}$ & $\begin{array}{c}\text { paired } \\
\text { t-test } \\
(p)\end{array}$ & $\begin{array}{l}\text { Pretest } \\
M \pm S D\end{array}$ & $\begin{array}{l}\text { Posttest } \\
\mathrm{M} \pm \mathrm{SD}\end{array}$ & $\begin{array}{c}\text { paired } \\
\text { t-test } \\
(p)\end{array}$ & & \\
\hline $\begin{array}{l}\text { Smartphone addiction } \\
\text { tendency }\end{array}$ & $\begin{array}{c}1.74 \pm \\
0.71\end{array}$ & $\begin{array}{c}1.10 \pm \\
0.15\end{array}$ & $\begin{array}{c}4.679 \\
(<.001)\end{array}$ & $\begin{array}{c}1.47 \pm \\
0.57\end{array}$ & $\begin{array}{c}1.69 \pm \\
0.52\end{array}$ & $\begin{array}{l}-1.873 \\
(.074)\end{array}$ & .445 & $\begin{array}{l}34.491 \\
(<.001)\end{array}$ \\
\hline Mental health & $\begin{array}{c}2.00 \pm \\
0.58\end{array}$ & $\begin{array}{c}1.16 \pm \\
0.24\end{array}$ & $\begin{array}{c}6.968 \\
(<.001)\end{array}$ & $\begin{array}{c}1.40 \pm \\
0.46\end{array}$ & $\begin{array}{c}1.85 \pm \\
0.57\end{array}$ & $\begin{array}{l}-4.083 \\
(.001)\end{array}$ & .457 & $\begin{array}{l}36.253 \\
(<.001)\end{array}$ \\
\hline Depression & $\begin{array}{c}1.84 \pm \\
0.58\end{array}$ & $\begin{array}{c}1.19 \pm \\
0.31\end{array}$ & $\begin{array}{c}5.960 \\
(<.001)\end{array}$ & $\begin{array}{c}1.40 \pm \\
0.49\end{array}$ & $\begin{array}{c}1.65 \pm \\
0.59\end{array}$ & $\begin{array}{l}-1.843 \\
(.078)\end{array}$ & .266 & $\begin{array}{l}15.551 \\
(<.001)\end{array}$ \\
\hline Anxiety & $\begin{array}{c}2.19 \pm \\
0.90\end{array}$ & $\begin{array}{c}1.19 \pm \\
0.32\end{array}$ & $\begin{array}{c}5.279 \\
(<.001)\end{array}$ & $\begin{array}{c}1.42 \pm \\
0.47\end{array}$ & $\begin{array}{c}1.94 \pm \\
0.64\end{array}$ & $\begin{array}{l}-3.853 \\
(.001)\end{array}$ & .378 & $\begin{array}{l}26.143 \\
(<.001)\end{array}$ \\
\hline Impulsivity & $\begin{array}{c}2.03 \pm \\
0.69\end{array}$ & $\begin{array}{c}1.14 \pm \\
0.26\end{array}$ & $\begin{array}{c}6.403 \\
(<.001)\end{array}$ & $\begin{array}{c}1.41 \pm \\
0.54\end{array}$ & $\begin{array}{c}1.86 \pm \\
0.63\end{array}$ & $\begin{array}{l}-3.729 \\
(.001)\end{array}$ & .452 & $\begin{array}{l}35.506 \\
(<.001)\end{array}$ \\
\hline Aggression & $\begin{array}{c}1.92 \pm \\
0.66\end{array}$ & $\begin{array}{c}1.14 \pm \\
0.30\end{array}$ & $\begin{array}{c}5.597 \\
(<.001)\end{array}$ & $\begin{array}{c}1.38 \pm \\
0.58\end{array}$ & $\begin{array}{c}1.96 \pm \\
0.79\end{array}$ & $\begin{array}{l}-4.049 \\
(<.001)\end{array}$ & .423 & $\begin{array}{l}31.522 \\
(<.001)\end{array}$ \\
\hline
\end{tabular}

Exp. $=$ Experimental group; Cont.$=$ Control group.

Table 4. Comparison of experimental and control groups over time $(\mathrm{N}=46)$

\begin{tabular}{|c|c|c|c|c|c|c|}
\hline \multirow{2}{*}{ Variables } & \multirow{2}{*}{ Time } & \multirow{2}{*}{ Exp. $(n=22)$} & \multirow{2}{*}{ Cont. $(n=24)$} & \multirow{2}{*}{$\begin{array}{l}\text { Between group } \\
\text { Group }\end{array}$} & \multicolumn{2}{|c|}{ Within group } \\
\hline & & & & & Time & Time $\times$ Group \\
\hline Variables & Time & $\mathrm{M} \pm \mathrm{SD}$ & $\mathrm{M} \pm \mathrm{SD}$ & $\mathrm{F}(\mathrm{p})$ & $\mathrm{F}(\mathrm{p})$ & $\mathrm{F}(\mathrm{p})$ \\
\hline \multirow{3}{*}{ Smartphone addiction tendency } & pretest & $1.74 \pm 0.71$ & $1.47 \pm 0.57$ & 9.655 & 3.111 & 19.820 \\
\hline & posttest & $1.10 \pm 0.15$ & $1.69 \pm 0.52$ & $(0.003)$ & $(0.049)$ & $(<0.001)$ \\
\hline & At 3 months & $1.15 \pm 0.20$ & $1.85 \pm 0.55$ & & & \\
\hline \multirow{3}{*}{ Mental health } & pretest & $2.00 \pm 0.58$ & $1.40 \pm 0.46$ & 5.088 & 5.695 & 31.028 \\
\hline & posttest & $1.16 \pm 0.24$ & $1.85 \pm 0.57$ & $(0.029)$ & $(0.006)$ & $(<0.001)$ \\
\hline & At 3 months & $1.37 \pm 0.47$ & $2.04 \pm 0.60$ & & & \\
\hline \multirow{3}{*}{ Depression } & pretest & $1.84 \pm 0.58$ & $1.40 \pm 0.49$ & 2.639 & 6.081 & 13.275 \\
\hline & posttest & $1.19 \pm 0.31$ & $1.65 \pm 0.59$ & $(0.111)$ & $(0.005)$ & $(<0.001)$ \\
\hline & At 3 months & $1.31 \pm 0.48$ & $1.88 \pm 0.67$ & & & \\
\hline \multirow{3}{*}{ Anxiety } & pretest & $2.19 \pm 0.90$ & $1.41 \pm 0.47$ & 1.189 & 2.430 & 25.229 \\
\hline & posttest & $1.19 \pm 0.32$ & $1.94 \pm 0.64$ & $(0.282)$ & $(0.094)$ & $(<0.001)$ \\
\hline & At 3 months & $1.50 \pm 0.60$ & $1.96 \pm 0.74$ & & & \\
\hline \multirow{3}{*}{ Impulsivity } & pretest & $2.03 \pm 0.69$ & $1.41 \pm 0.54$ & 5.372 & 3.621 & 35.871 \\
\hline & posttest & $1.14 \pm 0.26$ & $1.86 \pm 0.63$ & $(0.025)$ & $(0.031)$ & $(<0.001)$ \\
\hline & At 3 months & $1.32 \pm 0.51$ & $2.10 \pm 0.63$ & & & \\
\hline \multirow{3}{*}{ Aggression } & pretest & $1.92 \pm 0.66$ & $1.38 \pm 0.58$ & 7.233 & 4.119 & 24.478 \\
\hline & posttest & $1.14 \pm 0.30$ & $1.96 \pm 0.78$ & $(0.010)$ & $(0.023)$ & $(<0.001)$ \\
\hline & At 3 months & $1.34 \pm 0.50$ & $2.22 \pm 0.74$ & & & \\
\hline
\end{tabular}

Exp.=Experimental group; Cont. $=$ Control group. 


\section{Discussion}

This study was conducted to examine the effect of mind subtraction meditation on smartphone addiction tendency and mental health of elementary school third graders. The meditation program was offered to the students three times a week for eight weeks with each session about thirty minutes long. For smartphone addiction tendency, the experimental group who received the meditation program had a significant decrease. At three months after the meditation program ended, the tendency did increase, although remaining lower than their pretest scores. For the control group, smartphone addiction tendency at pretest was lower than the experimental group but the tendency increased posttest and also at 3 months. These results suggested that the tendency did decrease for the third graders who participated in the meditation program.

To date, there are very little studies on meditation and its effect on smartphone addiction tendency. Che and Park (2002) studied South Korean youth's internet use with Belief on Usage of Materials tool developed by Beck, Wright, Newman and Nies (1993). The findings of this study $(n=238)$ showed internet use belief scores and self-control scores measured using self-control rating scale (SCRS) were significantly improved after the meditation program. This finding was similar to a study by Yoo et al. (2014) on meditation youth camp participants' beliefs on internet usage and self-control.

The elementary school students' mental health (with its subsets of depression, anxiety, impulsivity, and aggression) was improved significantly as shown by the experimental group's posttest scores. Even after 3 months of completing the meditation program, their scores were lower (better) than the control group who did not participate in the program. The control group's mental health and its subset scores were seen increasing at posttest and also at 3 months.

The mind subtraction meditation explains that human beings accumulate their lived experiences within their minds (Woo, 1996). They record their lived experiences with their self-centered views in forms of 'pictures,' which includes an irrational attachment to negative emotions, continued fixed thoughts (obsessions), negative mindsets or frame of mind such as "I should have or I ought to have," fears, regrets, and others. Through eliminating and subtracting these 'pictures' and false selves which hold onto these 'pictures' from their minds, they can be released from their false minds and discover their true selves (Woo, 2009).

Jeong and Lee (2001) reports that mind subtraction meditation participants can expect expansions in their consciousness as much as they eliminate or cleanse their minds. Misperceptions or misinterpretations can be corrected as people start subtracting these pictures (Yoon et al., 2015) which can also minimize the emotional impact of these memories.

In this present study, it can be suggested that the third graders who participated in the meditation program were able to cleanse or subtract their minds of depression, anxiety, impulsivity, and aggression as well as smartphone addiction tendencies.

\section{Conclusion}

This study finds the meditation program had positive effects on smartphone addiction tendency and mental health of third graders in South Korea. Due to the beneficial effects found in this study, we recommend more development on utilizing the meditation programs in schools and other education settings. This study was first of its kind to study smartphone addiction tendency in South Korean elementary school students participating in the meditation program. We hoped to have provided some basis for further exploration and research into this new emergent addiction type (smartphone) related to technological advancement of today.

The following could be suggested based on the study's findings. First, even though the experimental group's measurements were taken after 3 months of the meditation program completion, the scores were still much better than the control group. For the participants of control group, their scores of smartphone addiction tendency and mental health were gradually increasing at posttest and at 3 months after. Therefore, to continue its positive effects, we believe it would be imperative to consistently offer such programs to the children in schools and other educational settings.

Secondly, it would be beneficial to develop such school-based meditation programs using the meditation method as a practical strategy to improve smartphone addiction tendency and mental health in children.

\section{Limitations and Recommendations for Future Research}

Some of the limitations of this study which would impact generalization of the findings include: small sample size, non- randomization of the groups, and geographical selection (a small city in South Korea). Future research studies are needed to verify and confirm the effects of school-based meditation programs on smartphone addiction 
tendencies and mental health variables. Additionally, other related research such as the brain and other neuropathophysiological studies would need to further examine the possible physiological basis for the smartphone addiction tendency.

\section{Acknowledgments}

The authors would like to thank Jin-Myung Lee for her valuable assistance with this research activity.

\section{Competing Interests Statement}

The authors have no funding or conflicts of interest to disclose.

\section{References}

An, L. W. (2006). The effect of maumsuryun meditation program on elementary school children's state anxiety. The Journal of Humanities, 11(2), 215-233.

Barnes, V. A., Bauza, L. B., \& Treiber, F. A. (2003). Impact of stress reduction on negative school behavior in adolescents. Health and Quality of Life Outcomes, 2013, 1, 10. https://doi.org/10.1186/1477-7525-1-10

Beauchemin, J., Hutchins, T. L., \& Patterson, F. (2008). Mindfulness meditation may lessen anxiety, promote social skills, and improve academic performance among adolescents with learning disabilities. Journal of Evidence-Based Complementary \& Alternative Medicine, 13(1), 34-45. https://doi.org/10.1177/1533210107311624

Benson, H., Kornhaber, A., Kornhaber, C., LeChanu, M. N., Zuttermeister, P. C., Myers, P., \& Friedman, R. (1994) Increases in positive psychological characteristics with a new relaxation-response curriculum in high school students. Journal of Research and Development in Education, 27(4), 226-231.

Choi, J. O. (2014). Analysis of influence of smartphone addiction practice on ADHD symptoms of elementary school students. Crisisonomy, 10(5), 159-178.

Choi, K. S., Lee, Y. S., \& Cheon, S. M. (2006). The effect of maumsuryun meditation training on neurotic middle school students' anger and anxiety. The Journal of Humanities, 11(1), 75-101.

Choi, N. S. (2013). The related factors in elementary school students'smartphone addiction: rearing attitudes of parents, self-esteem, and sociality (Master's thesis, Kyungnam University, South Korea).

Davey, S., \& Davey, A. (2014). Assessment of smartphone addiction in Indian adolescents: A mixed method study by systematic-review and meta-analysis approach. International Journal of Preventive Medicine, 5(12), 1500-1511.

Faul, F., Erdfelder, E., Lang, A. G., \& Buchner, A. (2007). G*Power 3: a flexible statistical power analysis program for the social, behavioral, and biomedical sciences. Behavior Research Methods, 39(2), 175-191. https://doi.org/10.3758/BF03193146

Haug, S., Castro, R. P., Kwon, M., Filler, A., Kowatsch, T., \& Schaub, M. P. (2015). Smartphone use and smartphone addiction among young people in Switzerland. Journal of Behavioral Addictions, 4(4), 299-307. https://doi.org/10.1556/2006.4.2015.037

Hong, J. H. (2013). The effect of elementary school students' use of smartphone on mental health and sociality: focusing on regulation effects of 5 personality factors (Master's thesis, Youngnam University, South Korea).

Hwang, K. H., \& Yoo, Y. S., \& Cho, O. H. (2012). Smartphone overuse and upper extremity pain, anxiety, depression, and interpersonal relationships among college students. Journal of the Korea Contents Association, 12(10), 365-375. https://doi.org/10.5392/JKCA.2012.12.10.365

Jeong, D. M., \& Lee, S. Y. (2001). Analysis of psychosomatic medicine effects and principle of maum meditation. Journal of the Korean Society of Jungshin Science, 5(2), 37-48.

Jeong, J. Y., Kim, J. H., Kim, M., \& Kim, J. I. (2015). The effects of maum meditation on hwa-byung symptoms, stress and coping styles. The Korean journal of stress research, 23(2), 63-77. https://doi.org/10.17547/kjsr.2015.23.2.63

Jun, D. S., \& Kim, D. W. (2015). The effects of smart phone addiction on mental health of adolescents and adults; focusing on the moderating effect of family support. Social Science Research Review, 31(3), 159-181. https://doi.org/10.18859/ssrr.2015.08.31.3.159

Jung, H. J. (2014). The effect of depression and anxiety on youth's smartphone addiction (Master's thesis, Mynugji University, South Korea). 
Jun, S. Y. (2013). The effect of art therapy program on aggression and toxicity of smartphone-addicted elementary school students (Master's thesis, Kwangju Women's University, South Korea).

Ju, S. J., \& Cho, S. S. (2015). A study on the discriminating factors of youth's smartphone addiction; focusing on daily average smartphone usage time, impulsivity, peer relationships, mother's authoritarianism - rearing attitudes. Journal of Youth Welfare, 17(1), 97-118.

Kang, H. Y., \& Park, C. H. (2012). Development and validation of the smartphone addiction inventory. Korean Journal of Psychology: General, 31(2), 563-580.

Kang, M. J. (2014). The relationship between the smartphone addiction and mental health of students with disabilities (Master's thesis, Pusan National University, South Korea).

Keum, C. M. (2013). Research into smartphone addiction proneness and mental health problem for middle and high school student at Korea (Master's thesis, Seoul National University, South Korea).

Kim, D., \& Ahn, H. (2006). A validation study of NEO personality assessment system (NEO-PAS) for adolescents. The Korea Journal of Youth Counseling, 14(1), 77-91.

Kim, D. H., Han, J. D., \& Park, K. J. (2014). The Relationships of smartphone addiction and mental health according to exercise hours of the after-school exercise in elementary school students. The Korean Journal of Elementary Physical Education, 20(2), 51-64.

Kim, D. K. (2013). An exploration study on elementary school students' smartphone use and educational strategies (Master's thesis, Jeju University, South Korea).

Kim, H. J. (2012). The effect of youth's smartphone addiction on school adaptation and social development (Master's thesis, Honam University, South Korea).

Kim, H. J., \& Yu, H. K., \& Jeong, Y. H. (2014). The group counseling program for the prevention of smartphone addiction for elementary school students. Journal of Learner-Centered Curriculum and Instruction, 14(5), $87-106$.

Kim, H. M. (2013). The effect of high school students' psychosocial health status and school adaptation on smartphone addiction (Master's thesis). Kyungbok University, South Korea.

Kim, H. S., Yu, H. K., \& Nam, S. Y. (2015). Development of a parents-involved group counseling program for the prevention of smartphone addiction in lower elementary school graders. The Journal of Child Education, 24(3), 131-150. https://doi.org/10.17643/KJCE.2015.24.3.08

Kim, J. M., \& Jung, J. B. (2005). The effects of empathy training program on the enhancement of empathy and bullying's degree for bullies. The Journal of Elementary Education Studies, 12(1), 19-45.

Kim, J. Y., \& Hwang, H. J. (2015). The mediating effects of self-control on the relationship between smartphone addiction and suicidal ideation in adolescents. Studies on Korean Youth, 26(4), 59-84. https://doi.org/10.14816/sky.2015.26.4.59

Kim, M. H. (2012). Comparison of the effect of maum meditation program on the depression, anxiety and self-esteem of the children and the juveniles. Journal of the Korea Contents Association, 12(4), 338-348. https://doi.org/10.5392/JKCA.2012.12.04.338

Kim, M. H., Lee, I. S., \& Yoo, Y. G. (2013). The effects of maum meditation program on the mental health and happiness of the undergraduates. Journal of Human Completion, 5, 33-55.

Kim, M. H., Yoo, Y. G., Lee, E. J., \& Son, M. K. (2013). The effect of maum meditation program on the aggression and autonomy of the children and the juveniles. Journal of Emotional \& Behavioral Disorders, 29(1), 145-171.

Kwak, J. Y. (2005). Educating for character through maum meditation at elementary school pupils. The Journal of Elementary Education, 15, 151-225.

Kwak, J. Y. (2009). Character change from meditation in male middle school students. Thesis Collection of Chinju National University of Education, 50, 41-67.

Kwon, Y. S. (2013). The relationship between internet overuse disorder and smartphone overuse disorder of middle school students: the moderating effects of depression and anxiety (Master's thesis, Cyber Graduate School of Joongbu University, South Korea).

Lee, I. S. (2009). Improvements in peer-relationship via maum meditation. Journal of Human Completion, 1, 
143-170.

Lee, J. W., Park, M. R., Lee, J. B., Lee, S. J., Park, E. S., \& Park, Y. J. (1998). A review on the methods of sample size determination in nursing research. Korean journal of women health nursing, 4(3), 375-387.

Lee, S. J. (2014). Analysis of smartphone addiction status and risk among elementary students. Journal of the Korean Association of Information Education, 18(2), 203-212. https://doi.org/10.14352/jkaie.2014.18.2.203

Lee, S. K. (2010). A study in the effects of maum meditation program on self-esteem of students in middle and high schools; focusing on the maum meditation youth camp. Journal of Human Completion, 2, 87-126.

Lee, S., Kang, H., \& Shin, G. (2015). Head flexion angle while using a smartphone. Ergonomics, 58(2), $220-226$. https://doi.org/10.1080/00140139.2014.967311

Lee, S. R. (2009). The effects of the maum meditation program on third grade children's self-esteem and self-efficacy. Journal of Human Completion, 1, 171-211.

Lin, Y. H., Chang, L. R., Lee, Y. H., Tseng, H. W., Kuo, T. B., \& Chen, S. H. (2014). Development and validation of the Smartphone Addiction Inventory (SPAI). PloS One, 9(6), e98312. https://doi.org/10.1371/journal.pone.0098312

Lin, Y. H., Lin, Y. C., Lee, Y. H., Lin, P. H., Lin, S. H., Chang, L. R., .. \& Kuo, T. B. (2015). Time distortion associated with smartphone addiction: Identifying smartphone addiction via a mobile application (App). Journal of Psychiatric Research, 65, 139-145. https://doi.org/10.1016/j.jpsychires.2015.04.003

McCutcheon, T., Schaar, G., \& Parker, K. L. (2016). Pender's Health Promotion Model and HPV Health-Promoting Behaviors among College-Aged Males: Concept Integration. Journal of Theory Construction \& Testing, 10(1), 12-19.

Ministry of Education, Science, and Technology. (2012). Manual for appropriate use of internet, smartphone and games. Retrieved from http://www.moe.go.kr/ko/board/download.do?boardSeq=69591

Ministry of Science, ICT, and Future Planning. (2015). 2014 results of internet addiction survey. Retrieved from http://www.msip.go.kr/cms/www/news/notice/_icsFiles/afieldfile/2015/04/14/2014\%EB\%85\%84_\%EC\% 9D $\%$ B8\%ED $\% 84 \%$ B0\%EB $\% 84 \%$ B7\%EC $\%$ A $4 \% 91 \%$ EB $\% 8 F \% 85 \%$ EC $\% 8 B \% A 4 \% E D \% 83 \% 9 C \%$ EC $\%$ A $1 \%$ B0\%EC $\% 82 \%$ AC_\%EA\%B2\%B0\%EA\%B3\%BC.hwp

Moon, H. K. (2013). The mediated effect of smartphone addiction, social anxiety, and self-absorption (Master's thesis). Sangji University, South Korea.

National Information Society Agency. (2013). 2013 national informatization white paper. Retrieved from http://eng.nia.or.kr/english/bbs/board_view.asp?BoardID=201112221611162611\&id=14345\&nowpage=1\& Order $=301 \&$ search_target $=\&$ keyword $=\&$ Flag $=\&$ objpage $=0$

Park, E. M., \& Park, K. H. (2014). The mediating effects of depression and aggression on the relationship between perceived parental rearing attitudes and smartphone addiction; a focus on gender differences. Korean Journal of Play Therapy, 17(2), 209-224.

Park, M. S. (2013). The effect of smartphone addiction and academic stress on high school students' mental health and self-esteem (Master's thesis, Soonchunhwang University, South Korea).

Park, S. M. (2013). The effect of middle school students' smartphone addiction on school adaptation and mental health (Master's thesis, Kukmin University, South Korea).

Park, J. E. (2013). The effect of smartphone addiction on youth (Master's thesis, Usan University, South Korea).

Park, Y. M. (2011). A study on adults'smartphone addiction and mental health (Master's thesis, Sangji University, South Korea).

Pender, N. (2011). The health promotion model manual. Retrieved from https://deepblue.lib.umich.edu/bitstream/handle/2027.42/85350/HEALTH_PROMOTION_MANUAL_Rev _5-2011.pdf

Roberts, J. A., Yaya, L. H., \& Manolis, C. (2014). The invisible addiction: Cell-phone activities and addiction among male and female college students. Journal of Behavioral Addictions, 3(4), $254-265$. https://doi.org/10.1556/JBA.3.2014.015

Rosaen, C., \& Benn, R. (2006). The experience of transcendental meditation in middle school students: a qualitative report. Explore, 2(5), 422-425. https://doi.org/10.1016/j.explore.2006.06.001 
Ryu, S. I., \& Cho, I. S. (2015). Factors affecting smartphone addiction among elementary school students. Journal of the Korea Academia-Industrial Cooperation Society, 16(9), 6180-6189. https://doi.org/10.5762/KAIS.2015.16.9.6180

Shin, S. C. (2014). Regulating effects of resilience toward the influence of smartphone toxication of elementary schoolchildren on adaptability to school life and aggression. The Journal of Child Education, 23(1), 199-214.

Smetaniuk, P. (2014). A preliminary investigation into the prevalence and prediction of problematic cell phone use. Journal of Behavioral Addictions, 3(1), 41-53. https://doi.org/10.1556/JBA.3.2014.004

So, K., \& Orme-Johnson, D. W. (2001). Three randomized experiments on the longitudinal effects of the transcendental meditation technique on cognition. Intelligence, 29(5), 419-440. https://doi.org/10.1016/S0160-2896(01)00070-8

Sun, H. G., \& Beak, J. S. (2015). The effects of participating in sport club activity for depression, aggressiveness and self-resilience of middle school students depending on the extent of smartphone addiction. Journal of Korean Society for the Study of Physical Education, 20(1), 107-123. https://doi.org/10.15831/JKSSPE.2015.20.1.107

Wisner, B. L., Jones, \& Gwin. (2010). School-based meditation practices for adolescents: a resource for strengthening self-regulation, emotional coping, and self-esteem. Children and Schools, 32(3), 150-159. https://doi.org/10.1093/cs/32.3.150

Wisner, B. L. (2008). The impact of meditation as a cognitive-behavioral practice for alternative high school students (Doctoral dissertation). University of Texas at Austin.

Woo, M. (1996). Woo Myung is the creator of the subtraction method taught in Ma-Eum-Soo-Ryun, which he founded in 1996. Retrieved from http://woomyung.com/woomyung/

Woo, M. (2009). The way to become a person in heaven while living. Seoul: Cham books.

Woo, M. (2013). Heaven's formula for saving the world. Seoul: Cham books.

Yoon, H. C., \& Eun, H. G. (2014). Validation study of the anxiety scale for middle graders at elementary school. Korean Journal of Counseling, 15(1), 359-370. https://doi.org/10.15703/kjc.15.1.201402.359

Yoon, Y. S. (2013). The relationship between middle school students'smartphone use and mental health: focusing on a school in eastern district education board of Incheon city (Master's thesis, Inhwa University, South Korea).

Yoo, Y. G., Lee, D. J., Lee, I. S., Shin, N. M., Park, J. Y., Yoon, M. R., \& Yu, B. (2016). The effects of mind subtraction meditation on depression, social anxiety, aggression, and salivary cortisol levels of elementary school children in South Korea. Journal of Pediatric Nursing, 31, e185-e197. https://doi.org/10.1016/j.pedn.2015.12.001

Yoo, Y. G., Lee, E. J., \& Jung, K. Y. (2013). The effects of maum meditation program on their school life in the lower grades in primary school children. The Journal of Child Education, 22(2), 139-160.

Yoo, Y. G., \& Lee, I. S. (2013). The effects of school-based maum meditation program on the self-esteem and school adjustment in primary school students. Global Journal of Health Science, 5(4), 14-27. https://doi.org/10.5539/gjhs.v5n4p14

Yoo, Y. G., Yoon, M. R., Choi, E. H., \& Kim, M. H. (2014). The effects of maum meditation program on juveniles' beliefs on internet usage and self-control. International Conference on Human Completion 2014, 101-104.

Yun, M. R., Choi, E. H., Kim, K. A., \& Yoo, Y. G. (2015). The effects of mind subtraction meditation on the decrease of depression, anxiety, and stress response of adults with depression. Journal of Wellness, 10(3), 109-121.

\section{Copyrights}

Copyright for this article is retained by the author(s), with first publication rights granted to the journal.

This is an open-access article distributed under the terms and conditions of the Creative Commons Attribution license (http://creativecommons.org/licenses/by/4.0/). 